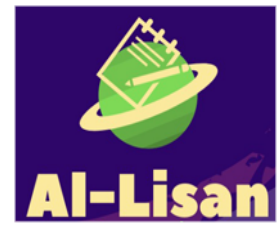

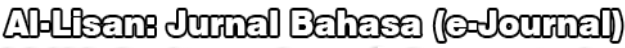

Lilli sultell lituet celchite

Volume 5, Nomor 2, Agustus 2020

ISSN 2442-8965 (P) ISSN 2442-8973 (E)

\title{
Error Analysis of English Abstract in International Journal of Economics, Business, and Accounting Research (IJEBAR)
}

\author{
Tira Nur Fitria \\ tiranurfitria@gmail.com \\ Institut Teknologi Bisnis AAS Indonesia
}

\begin{abstract}
This study aims to determine the types of errors and the most dominant type of errors in the International Journal of Economics, Business, and Accounting Research (IJEBAR) STIE AAS Surakarta, published in 2018. This study employed a qualitative method. The author used documents to collect data and analyzed the data by identifying errors, classifying errors, explanation errors, and tabulating errors. The research findings showed that the type of errors in IJEBAR was related to some aspects of writing, such as grammar, punctuation, and spelling. In the grammar aspect, there were 36 data or $50.70 \%$, which consist of some errors in class words (part of speech), for example in determiner/article (22 data or $61.11 \%$ ), verb (11 data or 30.56 $\%$ ), preposition ( 2 data or $5.56 \%$ ), and noun (1 data or $2.78 \%$ ). There were 21 data or $29.58 \%$ in the punctuation aspect, and in the spelling aspect, there are 14 data or $19.72 \%$. The most dominant type of errors found in IJEBAR is the aspect of grammar, as 36 data or $50.70 \%$. Errors can be caused by a lack of language skills such as the learner's lack of knowledge of the target language's correct rules or an error in translating using specific translation tools. Therefore, in writing English abstract well and correctly, it should follow the language (English) rule, which refers to the correct grammatical, punctuation, and spelling aspect.
\end{abstract}

Keywords: Error Analysis; Abstract Journal; Grammar; Punctuation; Spelling.

\section{A. INTRODUCTION}

One of the most important parts of a scientific article is the abstract (Mckee, 2020). Day \& Gastel (2006, p. 52) states that an abstract also usually viewed as a miniature version of the paper. It is a summarization of the important keys and points in a scientific paper, such as in thesis, dissertation, paper, report, journal, and article (Fitria, 2018c). An abstract is very important and necessary because it is part of the section of a paper that is written. Helmenstine (2019) states that an abstract is a concise summary of an experiment or research project. It should be written shortly or briefly. The abstract 
should provide an overview of the whole research described (Oliver, 2004, p. 13) and (Powner, 2014, p. 207).

The purpose of the abstract is to summarize the research paper by stating the goal/purpose of the research, the research method, the result/findings, and the last is a conclusion. Abstract should be brief and specific as possible, but still writing complete sentences that follow one another logically (Matthews et al., 2000, p. 68).

In other words, the readers who read an abstract should be able to understand why the writers conduct the study/research, how the writer conducts it, what the writer finds, and why the writer's work is important and necessary. Brown (2019) states that almost everyone knows what an abstract is. It is a short synopsis that precedes the short text of the journal article. The readers can find the article and maybe determined and decided whether they read it or not based on the abstract's wording (Bly, 2009, p. 5). This statement also supported by Kolin $(2013$, p. 696) that the readers maybe do not read entire the report, but almost the readers will read the abstract.

In the academic world, this abstract is used by educational institutions/institutions/ organizations as initial information on a study when it is included in the thesis, dissertation, journals, conferences, workshops, seminars, or others. Patrick (2014) defines that the abstract explains and describes both an unpublished or published research study in a certain form. It is a brief overview of the investigation or invention, so the other researchers can comprehend the content of the research. The information which usually provided in the abstract must be sufficient to help the other researchers in deciding whether the research is relevant to his/her interest or not. Therefore, abstract should be brief but not lacking in important elements necessary for the understanding of the research conducted. The abstract also helps the researchers decide whether to read the research paper in its entirety or not, even they can download it for necessity. The journal's abstracts are usually presented in English, or the combination of two languages, such as the Indonesian and English (Wulandari, 2014).

An abstract is a complete summary and explains the entire contents of scientific article. An abstract usually is placed at the beginning of the scientific article. Good abstract writing needs to be considered considering this section is part of the article that is read after the title. It is reasonable, whether or not a scientific article is read depends on the impression the reader gets when reading the abstract. The hardest part of the 
article to work on is abstract. An abstract in English is an absolute necessity that must exist (requirements in the accreditation of scientific journals). The overall goal of the abstract is to show how the proposed study will extend prior research in the area (Chasan-Taber, 2014, p. 287).

An abstract must be informative and descriptive, meaning that any information contained in the abstract must be based on facts. In other words, it is not permissible to include information that is not, in fact, clear in the content of an article in an abstract. The abstracts for an article should describe the topic, the purpose, thesis, or organizing construct and the scope of the article; the sources used and the conclusions (Klimova, 2013). Allen \& Hougland (2020) state that the abstract is written when a research is finished. An abstract usually is more appropriate for articles and research reports (Dumaine \& Healey, 2003, p. 2).

Scientific paper usually requires writing abstract English for each published text. Scriptwriters, in general, have completed their manuscripts with the intended abstract even though they are not all in English. From the abstracts compiled by the authors, perhaps still there are some problems and errors that need to be corrected or corrected for grammar, vocabulary, spelling, punctuation, or other aspects. Therefore, the correct spelling, grammar, and punctuation are important in writing English abstract (Fitria, 2018a).

The recent studies also focus on error analysis, such as first research entitled Error Analysis Found In the Students' Writing Composition of Simple Future Tense written by Fitria (2018) and second research entitled Errors in Students' Writing Composition in Simple Present Tense "My Daily Activity" written by Fitria (2019). Both of them, the research focus on error analysis in tenses such as simple present and simple future tense. Those research also have the same goal of the research, is to analysis the aspects of grammatical, punctuation, and spelling error. Other previous studies also written by Novita (2018) entitled "An Error Analysis on Undergraduate Thesis Abstracts of English Language Education Students of Sanata Dharma University”. This study to find out the mechanical and grammatical errors found in the undergraduate thesis abstracts. Concerning this study, the writer wants to study error analysis of English abstracts which has published in an international journal to find the errors. 
Error analysis has occupied an important key in linguistic (Spillner, 2017, p. 10). Error analysis also related to the process of deciding and determining the incidence, event, nature, cause, and effect/impact of an unsuccessful language (James, 2013). According to (Hamzah, 2012), the basis of the severity of errors can affect communication. Errors can be caused by lack of language skills such as the learner's lack of knowledge of the correct rules of the target language or an error in translating using certain translation tools.

IJEBAR is an International Journal of Economics, Business, and Accounting Research (IJEBAR). It is a peer-reviewed and open-access international scientific journal in the areas of Economic, Business, and Accounting theme. This analysis of research only focuses on a journal which published in 2018. Therefore, the researcher is interested to do the research analysis entitled "Error Analysis in the International Journal of Economics, Business, and Accounting Research (IJEBAR)”. Thus, based on the analysis problems, this study aims to find out the types of error and the most dominant type of errors found in the International Journal of Economics, Business, and Accounting Research (IJEBAR) STIE AAS Surakarta published in 2018.

\section{B. RESEARCH METHOD}

This research employs descriptive qualitative research. In general, basic qualitative research is providing a descriptive account to understand a phenomenon by using data that be collected in several ways (Ary et al., 2018). He also adds that the qualitative researcher focuses on how people make sense of or interpret the experience (Ary et al., 2009).

Data in this research were abstract. An abstract is a complete summary and explains the entire contents of scientific articles in a journal. While data source in this research is taken from International Journal of Economics, Business, and Accounting Research (IJEBAR) STIE AAS Surakarta which published in 2018, they are 1) Volume 2, No 01 (2018), 2) Volume 2, No 02 (2018), 3) Volume 2, No 03 (2018), 4) Volume 2, No 04 (2018). From that volume journal in 2018, there are 24 abstracts to be analyzed in this research.

The researcher uses the documentation for collecting data. According to Arikunto (2002), documentation is the technique to look for data about things or variables in 
some forms of fieldnotes, books, reports, newspapers, magazines, transcripts, inscriptions, dairy, and agendas for information under investigation. The purpose of documentation is to collect and complement and analyze the data that is not mentioned by the subject/object of the research and to know about how much data would be accounted for in the research.

According to Patton (2002), data analysis related to the process of selecting and arranging the order of the data, organize into a pattern, category, and description of each basic unit. In this research, the researcher analyses the errors found in IJEBAR journal published in 2018. The descriptions as follow: (1) Identifying errors. In this step, the researcher identifies the errors in IJEBAR journal published in 2018. (2) Classifying errors. In this step, the researcher classifies the errors into some writing aspects such as grammar, punctuation, and spelling. (3) Explanation errors. In this step, the researcher explains the source of error found. The writer tries to figure out the source of errors by predicting it if needed. (4) Tabulating of errors. In this step, the researcher draws the errors into a table/chart based on the classification of errors to tabulate the number of errors found in the journal and then figures out the most dominant errors in the journal. In tabulation data, the researcher uses a simple statistical analytical method, the proportion as a whole (100\%) then divided by the types of errors found in the journal. Then, the researcher counts the percentage frequency of each error occurrence by using the following formula below:

$\mathrm{Pi}=\frac{\mathrm{Fi}}{n} \times 100 \%$

Which: $\mathrm{Pi}=$ the proportion of the errors' frequency

$\mathrm{Fi}=$ frequency of each type of error

$\mathrm{n}=$ the total number of errors analyzed

\section{FINDINGS AND DISCUSSION}

\section{Findings}

Some writing errors are very common and frequently seen in abstract journals/articles. This research will explain details of the most common and easily avoidable writing errors such as spelling, punctuation, and grammar aspect. In IJEBAR journal published in 2018, there are some errors found in the aspect of spelling, punctuation, and grammar as follows: 
Tira Nur Fitria

Available online at http://journal.iaingorontalo.ac.id/index.php/al

\section{Grammar}

Grammar is the study of how to form words that has certain forms into a proper sentence. Or in other words, Grammar is a collection of structural rules that set the composition of words, phrases, and clauses in natural languages given. In this research, there are some errors found in IJEBAR journal in the aspect of grammar as follow:

Verb

Nordquist (2018b) defines that a verb is one of the parts of speech that describes an action or occurrence. It also can indicate a state of being.

Verb Error Data 1

...two independent variables has a positive effect on the value of the company.

Verb Error Data 2

The percentage based on variable empathy $t$ test and responsiveness have a significant positive effect on member satisfaction,..

Verb Error Data 2

The results of this study states that the orientation of innovation and competitive...

From three examples above show that there are some errors in the aspect of grammar, especially the verb. Verb error data 1 shows that the singular verb "has" does not fit with the plural subject "variables". It should be changed to the verb form for a suitable subject-verb agreement. Then, the correct form should be written: "have". In verb error data 2 shows that the verb "have" does not seem to agree with the subject "the percentage". It should be changed into an appropriate verb form. Then, the correct form should be written "has". While the verb error data 3 example shows that the singular verb "states" does not agree with the plural subject "results". It should be changed to the verb form for a suitable subject-verb agreement. Then, the correct form should be written "state".

Verb Error Data 4

....in order to obtains a sample of 10 chemical companies... 
Verb Error Data 5

In this study aims analyze the effect of financial ratios on the performance of cigarette companies listed on the IDX.

The data above show that there are some errors in the aspect of grammar, especially the using of main verb. The verb error data 4 shows that the verb "obtains" should be in the base form to-infinitive following "in order". It should be changed into the appropriate form. Then, the correct form should be written: "obtain". While the verb error data 5 shows that the verb "analyze" should be in the to-infinitive form. It should be added by the appropriate form. Then, the correct form should be written: "to analyze".

\section{Verb Error Data 6}

The purpose of this study was use to examine the effect of good corporate governance on company value.

The data above show that there are some errors in the aspect of grammar, especially the verb. Verb error data 6 appears that the form of the verb "use" does not work with "was" in this sentence. It should be changed into an appropriate verb in the form participle (V3) to make a passive form in this context. Then, the correct form should be written "was used".

\section{Verb Error Data 7}

The number of samples in this study were 45 samples.

The data above show that there are some errors in the aspect of grammar, especially the verb. The verb error data 7 shows that the verb "were" does agree with the subject "the number of samples in this study". It should be changed into the appropriate verb. Then, the correct form should be written "was".

Verb Error Data 8

...in predicting financial distress in go public company automotive sub sector and component 2012-2016 periods.

The data above show that there are some errors in the aspect of grammar, especially the verb. The verb error data 8 shows that the verb "go" is written into the 
Tira Nur Fitria

Available online at http://journal.iaingorontalo.ac.id/index.php/al

wrong form after the preposition "in". It should be changed into the gerund form (V+ing). Then, the correct form should be written: "going".

\section{Determiner/Article}

Determiner/article is a word or a group of words that specifies, identifies, or quantifies the noun or the noun phrase that follows it (Nordquist, 2018a).

Determiner Error Data 1

This research uses qualitative method that is by obtaining company data then compare the method used.

Determiner Error Data 2

Based on hypothesis test by using significant level $\alpha=0,05$ result of $\boldsymbol{F}$ test,..

Determiner Error Data 3

...means independent variable that is application of sharia principles and service

Determiner Error Data 4

This study examines the effect of performance audit of the government...

The four examples above show that there are some errors in the aspect of grammar, especially determiner/article. From four examples above show that the noun phrase which is written bold seems to be missing a determiner/article before it. It should be added by the appropriate article "a" or "the". In the first example, the noun phrase "qualitative method" should be written "a qualitative method" or "the qualitative method". In the third example, the noun phrase "F test" should be written "an F test" or "the F test". In the fifth example, the noun phrase "application of sharia principles and service" should be written "an application of sharia principles and service" or "the application of sharia principles and service". Then, in the thirteenth example, the noun phrase "performance audit" should be written "a performance audit" or "the performance audit". 
Tira Nur Fitria

Available online at http://journal.iaingorontalo.ac.id/index.php/al

\section{Noun}

A noun is a part of speech that names or identifies a person, place, and thing, It also can identify a quality, idea, thought, or activity.

Noun Error Data 1

The results shows that there was a difference between company method and full costing method,...

The example above shows that there is an error in the aspect of grammar, especially in the noun. The example above shows that the singular verb shows do not appear to agree with the plural subject "results". Therefore, it should be changed into an appropriate verb form of the subject-verb agreement. The correct form should be written "show".

\section{Preposition}

Nordquist (2018c) defines that preposition is a word that refers to the relationship between a noun, pronoun, and other words in a sentence.

\section{Preposition Error Data 1}

...or can be seen from the significance value $0.172>=0.05$

Preposition Error Data 2

The purpose sampling method was used and determined 100 samples.

The two examples above show that there are some errors in the aspect of grammar. In the first example shows that there is a missing preposition after the word "value". It should be added by the preposition, then it is written "value of". While the second example shows that there is a missing preposition after the word "determined". It should be added by the correct preposition, then the correct form should be written: "determined by".

\section{Punctuation}

Punctuation is a system of signs or symbols given to readers to show how sentences are made and how they should be read. English punctuation which is most commonly used includes full stop, comma (point), an ellipsis (dots), colon, semicolon, question mark (question mark), an exclamation mark (sign exciting), quotation marks (hyphen), a hyphen, slash, parentheses (brackets), an apostrophe.

Punctuation Error Data 1

In this study the influence of pritability is activity while liquidity and solvency do not affect profitability. 
Punctuation Error Data 2

In the year 2015 there are 2 companies i.e. IMAS, GDYR and 2016 year whereas LPIN is GDYR, IMAS and PRAS.

The example above shows that there are some errors in the aspect of grammar. In the 1st example appears that there is missed a comma after the introductory phrase of "in this study". It should be added by a comma, then the correct form should be written: "In this study, ...". While in the 17 th example appears that there is missed a comma after the introductory phrase "In the year 2015". It should be added by a comma, then the correct form should be written: "In the year 2015, ...".

Punctuation Error Data 3

While testing the hypothesis using $F$ test for simultaneous test and $\boldsymbol{t}$ test partially,...

Punctuation Error Data 4

... a significant effect on the Original Revenue of District / City Regions in the Surakarta Residency.

Punctuation Error Data 5

...in predicting financial distress in go public company automotive sub sector and component 2012-2016 periods.

The example above shows that there are some errors in the aspect of grammar. In the 3rd example appears that the word "t-test" is missing a hyphen. It should be added by the hyphen(s). Therefore, the correct form should be written "t-test". In the 15 th example appears that the word "City Regions" is missing a hyphen. It should be added by the hyphen(s). Therefore, the correct form should be written "City-Regions". While In the 15th example appears that the word "sub sector" is missing a hyphen. It should be added by the hyphen(s). Therefore, the correct form should be written "sub-sector".

\section{Spelling}

Spelling is the rules of how to describe sounds (words, phrases, sentences, etc.). English spelling includes the addition or fusion of letters in a word ending in a certain letter, abbreviated writing with correct punctuation.

Spelling Error Data 1

To determine the effect of cash flows from operating activities, cash flows from investment activities and cash flows... 
Spelling Error Data 2

...show that together regression model can be used to explain the relation between Return on Asset,...

Spelling Error Data 3

the application effect of sharia principles and service againts customer satisfaction level...

Spelling Error Data 4

Based on the F test shows that the significance number is...

Spelling Error Data 5

The purpose sampling method was used and determined 100 samples.

Spelling Error Data 6

The method used to analyze the leading sectors in this research is location quotient and shiftshare analysis...

The examples above show that there are some errors in the aspect of spelling. In the 2nd example appears that the word "investment" does not seem to fit in this context. It should be replaced with a different one. Therefore, the correct form should be written: "investing". While in the 3rd example appears that the word "relation" also does not seem to fit in this context. It should be replaced with a different one. Therefore, the correct form should be written "relationship". In the 5th example appears that the word "againts" is not in the dictionary or perhaps the spelling is incorrect. It should be replaced with the appropriate word to prevent future alerts. Therefore, the correct form should be written "against". In the 9th example appears that the word "significance" does not seem fit in this context. Therefore, the correct form should be written "significant". In the 10th example appears that the word "purpose" does not seem fit in this context. Therefore, the correct form should be written "purposive". While in the 12th example appears that the word "shiftshare" is not in the dictionary. Therefore, the correct form should be written by adding space between "shift" and "share" to be "shift share". 
Spelling Error Data 7

...earnings per share and dividend pay out ratio to stock returns on manufacturing companies...

From the examples above shows that there are some errors in the aspect of spelling. The spelling error data 7 appears that the word "pay out" seems to be miswritten in this context. It should be replaced with appropriate word to fit in this sentence. Therefore, the correct form should be written without spacing between "pay" and "out" into "payout".

\section{Discussion}

Some points of good writing usually include grammar, spelling, punctuation, and capitalization (MacMillan, 2017). By mastering these rules and conventions, it makes the writing easier to be understood by the readers. This research will identify the type of errors and find out the most dominant type of errors written in IJEBAR journal published in 2018. Below the table of the result of students' writing composition, it is found of errors, such as in grammar, punctuation, and spelling. The table as follow:

Table 1. Frequency of Error in Abstract of IJEBAR Journal Aspect of Error Analysis

\begin{tabular}{lllllll}
\cline { 2 - 5 } Aspect & \multicolumn{4}{c}{ Grammar } & Punctuation & Spelling \\
\cline { 2 - 5 } & $\begin{array}{l}\text { Determiner/ } \\
\text { Article }\end{array}$ & Verb & Preposition & Noun & & \\
\cline { 1 - 5 } & 22 & 11 & 2 & 1 & \\
& $61.11 \%$ & $30.56 \%$ & $5.56 \%$ & $2.78 \%$ & & \\
\cline { 1 - 4 } TOTAL & & & 36 & $\mathbf{2 1}$ & $\mathbf{1 4}$ \\
\hline$\%$ & $50.70 \%$ & & & $29.58 \%$ & $19.72 \%$
\end{tabular}

From the table above, it shows that the type errors in IJEBAR journal published in 2018 include writing aspects, they are grammar, punctuation, and spelling. In grammar aspect, it is found $=36$ data or $50.70 \%$, which show some errors in class words (part of speech) such as in part of determiner/article (22 data or $61.11 \%$ ), verb (11 data or 30.56 $\%$ ), preposition (2 data or $5.56 \%$ ), and noun (1 data or $2.78 \%$ ). In the punctuation aspect, it is found 21 data or $29.58 \%$, and in the spelling aspect, it is found 14 data or $19.72 \%$. While, the most dominant type of errors found in IJEBAR journal published in 2018 is an aspect of grammar, there are 36 data or $50.70 \%$. In punctuation as 21 data or 
29.58, then in spelling as 14 data or $19.72 \%$. Below the description of the students' writing composition as follow:

Grammar is related to the system of the language itself. Not only understanding how language works but by learning the grammar of a language, it will make better writing. Grammar errors in English that often occur are related to the inability of learners to process and arrange the sentences they make. In this research, there are some errors in the aspect of grammar, such as in some parts of speech (class word). First, in determiner, some noun phrases are written bold seem to be missing a determiner/article before it. Therefore, it should be added by the appropriate article "a" or "the". For example, in the noun phrase "qualitative method", "application of sharia principles and service" and "performance audit". The other examples are must be written into correct word with determiner/article "a" or "the", like in "the cost", "the full", "the writer", "an independent", "a partially", "the price", “a stock", "a simple", "the economic", "an expert", or "the audit". In verb, there are some singular verb does not fit with the plural subject or vice versa. Therefore, it should be changed to the other verb form for appropriate subject-verb agreement. For example, the singular "the plural subject "variables" should be changed into "have", The verb "have" does not seem to agree with the subject "the percentage". Therefore, it should be changed into "has", and the singular verb "states" do not agree with the plural subject "results". Therefore, it should be changed to "state". In preposition, there is a missing preposition after the word "value" and "determined". It should be added by the preposition, then it is written "value of" and "determined by".

Punctuation is a sign of how structure, organization, intonation, and pauses can be observed in reading. Punctuation means giving the right punctuation in the right place to show the exact length of the sentence and its meaning. Providing proper punctuation in English is important to make it easier for readers to understand what is written. In this research, there are some errors in the aspect of punctuation. There is missing a comma after the introductory phrase of "in this study" and "In the year 2015". It should be added by a comma, then the correct form should be written "In this study" and "In the year $2015, \ldots$.. Then, the other example shows that there are some words are missing a hyphen, such as "t test", "City Regions" and "sub sector". Therefore, it should be added 
by the hyphen(s). Therefore, the correct form should be written "t-test", "City-Regions" and "sub-sector".

Spelling is the rules of how to describe sounds (words, phrases, sentences, etc.) in the form of writing and the use of punctuation. It includes vowel, consonant, silent letter, prefix, suffix, contraction, homonym, synonym, etc. In this research, there are some errors in the aspect of spelling. There are some words do not seem to fit in this context of the sentence. For example, the word "investment", should be written, "investing". The word "relation" should be written "relationship". The word "significance" should be written "significant". The word "purpose" should be written "purposive". The word "againts" is not in the dictionary or perhaps the spelling is incorrect. It should be replaced and written "against". Then, the word "pay out" seems to be miswritten in this context. It should be written without spacing between "pay" and "out" into "payout".

Errors can be caused by a lack of language skills such as the learner's lack of knowledge of the target language's correct rules or an error in translating using certain translation tools. As stated by Heydari \& Bagheri (2012) that the errors made by the students can be from both from the intra-language and interlanguage interference. This is while the errors caused by mother tongue interference were in a small proportion. Interlingual errors include errors in choosing vocabulary and composing sentences caused by the influence of the native language. While intralingual errors in the form of omissions or improper additions to the form of words or sentence forms. Interlingual errors are caused by the process/mechanism of transfer and borrowing from the learners' LI to L2. Intralingual errors are attributed to the processes/mechanisms of some factors.

\section{CONCLUSIONS}

Based on the analysis, it shows that the type errors found in the International Journal of Economics, Business, and Accounting Research (IJEBAR) STIE AAS Surakarta published in 2018 covers of three important aspects of writing, such as in grammar (structure), punctuation, and spelling aspect. In the grammar aspect, it is found 36 data or $50.70 \%$, which consist of some errors in class words (part of speech) especially in determiner/article (22 data or $61.11 \%$ ), verb (11 data or $30.56 \%$ ), preposition ( 2 data or $5.56 \%$ ), and noun ( 1 data or $2.78 \%$ ). In the punctuation aspect, it 
is found 21 data or $29.58 \%$, and in the spelling aspect, it is found 14 data or $19.72 \%$. While the most dominant type of errors found in IJEBAR journal published in 2018 is an aspect of grammar, it is found 36 data or $50.70 \%$.

Errors can be caused by lack of language skills such as the learner's lack of knowledge of the target language's correct rules or an error in translating using certain translation tools. Related to the analysis in this research, the writer offers some suggestions related to the error analysis. It would be better for the authors if making an abstract of English is done at the final stage, where all parts of the article for publication have been completed in abstract writing in English. The part that is often a standard error of the writers/authors in translating abstract English is the incorrect use of language, punctuation, and correct spelling. For the other researchers. The result of this study may be used as reference and information to conduct further researches with the same topic. This research can also contribute to writing a good and proper abstract based on the language (English) rule, which refers to the correct grammatical, punctuation, and spelling. 


\section{REFERENCES}

Allen, J. M., \& Hougland, S. (2020). The SAGE Guide to Writing in Criminal Justice Research Methods. SAGE Publications.

Ary, D., Jacobs, L. C., Irvine, C. K. S., \& Walker, D. (2018). Introduction to Research in Education. Cengage Learning.

Ary, D., Jacobs, L. C., Razavieh, A., \& Sorensen, C. K. (2009). Introduction to Research in Education. Cengage Learning.

Bly, R. (2009). 88 Money-Making Writing Jobs. Sourcebooks, Inc.

Brown, A. B. (2019, September 1). Crafting Abstracts to Define Your Article's Scope and Significance. https://preciouswecare.nl/?p=2118

Chasan-Taber, L. (2014). Writing Dissertation and Grant Proposals: Epidemiology, Preventive Medicine and Biostatistics. CRC Press.

Day, R. A., \& Gastel, B. (2006). How to Write and Publish a Scientific Paper. Cambridge University Press.

Dumaine, D., \& Healey, E. C. (2003). Instant-Answer Guide to Business Writing: An A$Z$ Source for Today's Business Writer. iUniverse.

Fitria, T. N. (2018a). Error Analysis Found in Students' Writing Composition of Simple Future Tense. ELS Journal on Interdisciplinary Studies in Humanities, 1(3), 240-251.

Fitria, T. N. (2018b). Error Analysis Found in Students' Writing Composition of Simple Future Tense. ELS Journal on Interdisciplinary Studies in Humanities, 1(3), 240-251.

Fitria, T. N. (2018c). TRANSLATION TECHNIQUE OF ENGLISH ABSTRACT TRANSLATION IN JOURNAL EDUNOMIKA IN 2018. English and Literature Journal, 5(2), 145-160.

Fitria, T. N. (2019). ERRORS IN STUDENTS' WRITING COMPOSITION IN SIMPLE PRESENT TENSE "MY DAILY ACTIVITY." EDULANGUE, 2(1), 47-62. https://doi.org/10.20414/edulangue.v2i1.318 
Hamzah, H. (2012). An Analysis of The Written Grammatical Errors Produced By Freshment Students In English Writing. Lingua Didaktika: Jurnal Bahasa Dan Pembelajaran Bahasa, 6(1), 17. https://doi.org/10.24036/ld.v6i1.3127

Helmenstine, A. M. (2019, June 26). Find out How to Write an Abstract for a Scientific Paper. ThoughtCo. https://www.thoughtco.com/writing-an-abstract-for-ascientific-paper-609106

Heydari, P., \& Bagheri, M. S. (2012). Error Analysis: Sources of L2 Learners' Errors. Theory and Practice in Language Studies, 2(8), 1583-1589. https://doi.org/10.4304/tpls.2.8.1583-1589

James, C. (2013). Errors in Language Learning and Use: Exploring Error Analysis. Routledge.

Klimova, B. F. (2013). Common Mistakes in Writing Abstracts in English. Procedia Social and Behavioral Sciences, 93, 512-516. https://doi.org/10.1016/j.sbspro.2013.09.230

Kolin, P. C. (2013). Successful Writing at Work. Cengage Learning.

MacMillan, G. (2017, February 4). The Importance of Grammar, Punctuation, Spelling, and Capitalization. Linkedin. https://www.linkedin.com/pulse/importancegrammar-punctuation-spelling-gregg-macmillan/

Matthews, J. R., Bowen, J. M., \& Matthews, R. W. (2000). Successful Scientific Writing Full Canadian Binding: A Step-by-Step Guide for the Biological and Medical Sciences. Cambridge University Press.

Mckee, K. (2020, March 5). How to Write a Scientific Abstract. Wiley. https://www.wiley.com/network/researchers/preparing-your-article/how-towrite-a-scientific-abstract

Nordquist, R. (2018a, August 31). What Is a Determiner in English Grammar? ThoughtCo. https://www.thoughtco.com/determiner-in-grammar-1690442

Nordquist, R. (2018b, October 30). Learn What a Verb Is in English and How It's Used In a Sentence. ThoughtCo. https://www.thoughtco.com/verb-definition-1692592

Nordquist, R. (2018c, December 24). How Prepositions Build Relationships Between Words. ThoughtCo. https://www.thoughtco.com/preposition-english-grammar1691665 
Novita, V. (2018). An error analysis on undergraduate thesis abstracts of English Language Education Students of Sanata Dharma University [Skripsi, Sanata Dharma University]. https://repository.usd.ac.id/32689/

Oliver, P. (2004). Writing Your Thesis. SAGE.

Patrick, R. (2014, May 19). 4 Elements of a Good Abstract-SimplyEducate.Me. Simply Educate. https://simplyeducate.me/2014/05/19/4-elements-of-a-good-abstract/

Powner, L. C. (2014). Empirical Research and Writing: A Political Science Student's Practical Guide. CQ Press.

Wulandari, I. (2014). Grammatical Errors Found In Articles' Abstracts Of Indonesian Scholarly Journals. JEELS (Journal of English Education and Linguistics Studies), 1(1). https://doi.org/10.30762/jeels.v1i1.33 